\title{
Orexin-A Depolarizes Dissociated Rat Area Postrema Neurons through Activation of a Nonselective Cationic Conductance
}

\author{
Bo Yang and Alastair V. Ferguson \\ Department of Physiology, Queen's University, Kingston, Ontario, Canada K7L 3N6
}

The area postrema (AP) is involved in the regulation of body fluid balance, feeding behavior, and cardiovascular function. Orexin (ORX)-A is a 33 aa peptide that regulates energy metabolism and sympathetic and cardiovascular actions. ORX immunoreactive axons and their varicose terminals have been found in AP. In this study, whole-cell, current- or voltage-clamp recordings were obtained from 108 dissociated rat AP neurons. The mean resting membrane potential of these neurons $(n=48)$ was $-59.24 \pm 0.87 \mathrm{mV}$, the mean input resistance was $3.57 \pm$ $0.22 \mathrm{G} \Omega$, and the action potential amplitude of these cells was always $>90 \mathrm{mV}$. Current-clamp studies showed bath application of ORX-A depolarized the majority of AP neurons tested (68.8\%; 33 of 48$)$, whereas small proportions of cells were either hyperpolarized (16.7\%; 8 of 48 ) or unaffected $(14.6 \% ; 7$ of 48 ). These depolarizing effects were found to be concentration dependent from $10^{-8}$ to $10^{-11} \mathrm{M}$. We then examined the contributions of specific ionic conductances to the ORX-Ainduced excitation of AP neurons through whole-cell, voltageclamp studies. Our results demonstrate that in contrast to previous studies on other neuronal populations, ORX-A did not affect net whole-cell potassium currents in AP neurons. Slow depolarizing voltage ramps, however, revealed that ORX-A enhanced a nonselective cationic conductance in AP neurons, effects which would explain the depolarizing effects of the peptide. These data demonstrate that AP neurons are directly influenced by ORX-A and suggest that ORX-A may exert its effects on the central control of feeding behavior and cardiovascular function through direct actions in AP.

Key words: area postrema; orexin-A; patch-clamp; nonselective cationic conductance; electrophysiology; central control of feeding behavior; cardiovascular function
Orexins (ORX-A and -B)/hypocretins (hypocretin-1 and -2) are novel neuropeptides discovered in 1998 (de Lecea et al., 1998; Sakurai et al., 1998) that include two separate peptides proteolytically derived from the same precursor protein (Sakurai et al., 1998). Orexin-producing neurons are exclusively distributed within and around the lateral hypothalamic area (LHA), the dorsomedial hypothalamic nucleus (DMH), and the perifornical nucleus in rats (de Lecea et al., 1998), areas which have been implicated previously in the control of mammalian feeding behavior (Marshall and Teitelbaum, 1974; Oltmans and Harvey, 1976). Central administration of orexins stimulates feeding (Sakurai et al., 1998) and drinking (Kunii et al., 1999) in rats and mice and affects the behavioral satiety sequence in rats (Rodgers et al., 2000). Therefore, orexins are recognized as potent orexigenic peptides.

Although immunohistochemical studies using anti-ORX antiserum have shown ORX-immunoreactive (IR) neurons specifically localized within the perifornical nucleus, LHA, DMH, and posterior hypothalamic area (de Lecea et al., 1998), ORX-IR axons and their varicose terminals show a widespread distribution throughout the entire adult rat brain, including the cerebral cortex, circumventricular organs (CVOs) [the subfornical organ and the area postrema (AP)], limbic system, and brain stem

Received Feb. 11, 2002; revised April 1, 2002; accepted April 11, 2002.

This work was supported by a grant to A.V.F. from the Heart and Stroke Foundation of Ontario. We thank Dr. J. W. Anderson for helpf ul comments on this manuscript.

Correspondence should be addressed to Dr. A. V. Ferguson, Department of Physiology, Queen's University, Kingston, Ontario, Canada K7L 3N6. E-mail: FergusnA@post.queensu.ca.

Copyright (C) 2002 Society for Neuroscience $0270-6474 / 02 / 226303-06 \$ 15.00 / 0$
(Peyron et al., 1998). These results indicate that the ORX system provides a link between the hypothalamus and other brain regions and plays important roles in integrating the complex physiology underlying feeding behavior and other autonomic functions. In addition to effects on feeding, centrally administered orexins have also been demonstrated to have sympathetic and cardiovascular actions (Shirasaka et al., 1999), play a key role in the regulation of rapid eye movement sleep and the pathophysiology of narcolepsy (Reilly, 1999; Bourgin et al., 2000), and activate the hypothalamo-pituitary-adrenal axis (Kuru et al., 2000). Therefore, orexin neurons project throughout the entire CNS to nuclei known to be important in the control of feeding, sleep-wakefulness, neuroendocrine homeostasis, and autonomic regulation. In addition, genetic ablation of orexin neurons in mice resulted in narcolepsy, hypophagia, and obesity (Hara et al., 2001).

The area postrema is a midline structure located on the floor of the caudal end of the fourth ventricle and is one of the most highly vascularized regions in the brain (Wislocki and Putnam, 1920). In addition, this circumventricular organ lacks the typical blood-brain barrier that is normally impermeable to most bloodborne peptides (Leslie, 1986). In addition to the description of AP as a chemosensitive trigger zone (for review, see Borison, 1974), this structure has also been shown to regulate central autonomic control (Ferrario et al., 1979; Ferguson and Marcus, 1988), body fluid balance, and feeding (Edwards and Ritter, 1981; Hyde and Miselis, 1983).

These studies combined with reports of immunoreactive ORX in the AP suggest this CVO as a potential CNS site, where ORX-A acts to influence central autonomic control. The present 
study uses whole-cell, patch-clamp techniques to examinewhether ORX-A directly affects AP neurons and to elucidate the membrane events underlying such actions.

\section{MATERIALS AND METHODS}

Cell dissociation. Cell dissociation and culture methods were modified from those of Ferguson et al. (1997). In brief, adult (100-150 gm) male Sprague Dawley (Charles River, Quebec, Canada) rats were decapitated, and the brains were rapidly removed and immersed in ice-cold Hanks' buffer (nominally $\mathrm{Ca}^{2+}$ - and $\mathrm{Mg}^{2+}$-free). Under a dissecting microscope, the AP is visually identified (superficial location at the level of the fourth ventricle, its v-shaped appearance, and its distinguishing shallow orange color), cut away from the surrounding tissue, placed in $1.5 \mathrm{ml}$ of the same solution containing $1 \mathrm{mg} / \mathrm{ml}$ trypsin (Sigma, St. Louis, MO), and warmed to $37^{\circ} \mathrm{C}$. After incubation (in $5 \% \quad \mathrm{CO}_{2} / 95 \% \quad \mathrm{O}_{2}$ at $37^{\circ} \mathrm{C}$ ) and periodic gentle shaking at $5 \mathrm{~min}$ intervals for $15-20 \mathrm{~min}$, the AP was gently triturated through a tuberculin syringe fitted with a 20 gauge needle. The cell suspension was transferred to a Hanks' solution containing $\mathrm{Ca}^{2+}(1.3$ $\mathrm{mm}), \mathrm{Mg}^{2+}(0.9 \mathrm{~mm})$, and $0.1 \%$ bovine serum albumin (BSA) (Sigma type A-6003, essentially fatty acid-free) at room temperature $\left(22^{\circ} \mathrm{C}\right.$ $24^{\circ} \mathrm{C}$ ). After centrifugation, the pellet was resuspended in this same solution and recentrifuged. The resultant pellet was again resuspended in the BSA-containing solution, plated onto plastic Petri dishes, and placed within a $5 \% \mathrm{CO}_{2} / 95 \% \mathrm{O}_{2}$ environment at $37^{\circ} \mathrm{C}$ until the cells attached to the dish $(\sim 1 \mathrm{hr})$. The Petri dishes were then further filled with Neurobasal-A media (Invitrogen Canada, Inc., Ontario, Canada), which contained antibiotics $(100 \mathrm{U} / \mathrm{ml}$ penicillin/streptomycin; Invitrogen Canada, Inc.) and was additionally supplemented with $0.5 \mathrm{~mm}$ L-glutamine (Invitrogen Canada, Inc.). The cells were maintained in the $\mathrm{CO}_{2}$ incubator at $37^{\circ} \mathrm{C}$ until use (12 hr to $3 \mathrm{~d}$ after dissociation). All procedures conformed to the standards outlined by the Canadian Council on Animal Care and the Queen's University Animal Care Committee.

Experimental solutions. For current-clamp recording and measurement of the nonselective cation current as well as the $\mathrm{K}^{+}$conductances during voltage-clamp recordings, the pipette solution contained (in $\mathrm{mM}$ ): 130 potassium-gluconate, 10 EGTA, $1 \mathrm{MgCl}_{2}, 10 \mathrm{HEPES}, 4 \mathrm{Na}_{2} \mathrm{ATP}$, and 0.1 GTP, pH adjusted to 7.2 with KOH. Tetrodotoxin (TTX) $(0.1 \mu \mathrm{M})$ was added to the external solutions to block voltage-gated sodium channels. The control bath solution consisted of artificial CSF (aCSF) of the following composition (in $\mathrm{mM}$ ): $140 \mathrm{NaCl}, 5 \mathrm{KCl}, 2 \mathrm{CaCl}_{2}, 1 \mathrm{MgCl}_{2}, 10$ HEPES, and 10 glucose, $\mathrm{pH}$ adjusted to 7.4 with $\mathrm{NaOH}$. All chemicals, unless otherwise stated, were obtained from Sigma.

Electrophysiological methods. Whole-cell, patch-clamp recordings were obtained from cells defined as neurons by the presence of $\geq 90 \mathrm{mV}$ action potentials in response to a depolarizing pulse (current-clamp recordings) or by the presence of large rapid voltage-activated inward currents that were blocked by TTX (voltage-clamp recordings). Electrodes/micropipettes of 3-5 M $\Omega$ were pulled from TW150 glass (World Precision Instruments, Sarasota, FL) on a horizontal Flaming/Brown micropipette puller (model P-87; Sutter Instrument Co., Novato, CA), fire-polished, and filled with the appropriate filling solution. Signals were amplified, collected, and processed using an Axopatch 200B (Axon Instruments, Foster City, CA) amplifier and a 1401plus analog-to-digital interface and Signal and Spike2 software packages from Cambridge Electronic Design (Cambridge, UK). The recording chamber was the $35 \mathrm{~mm}$ plastic Petri dish in which the cells had been cultured, and solution changes were made by a gravity-fed perfusion system. This flow was adjusted to $\sim 3$ $\mathrm{ml} / \mathrm{min}$ and was maintained constant throughout the entire recording period.

Definition of response. The membrane potential and firing frequency (20 sec bins) of cells were measured for $1 \mathrm{~min}$ before and for $\leq 2 \mathrm{~min}$ after change in bath solutions, with ORX-A being applied to the recording dishes via perfusion lines. Membrane potential changes were assessed by evaluating changes expressed in relation to the average of the $60 \mathrm{sec}$ control period for at least three consecutive $20 \mathrm{sec}$ time periods after experimental treatments.

Statistical analysis. For statistical analysis of the effects of ORX-A on AP neuronal properties, means were calculated from cells that were determined to have been affected using the above criteria. Changes in input resistance and peak and steady-state conductance in response to ORX-A were compared using the Student's $t$ test. All values are plotted as means \pm SEM. The concentration-response curve was constructed from a sigmoidal function of nonlinear regression (Prism; GraphPad Software Inc., San Diego, CA).

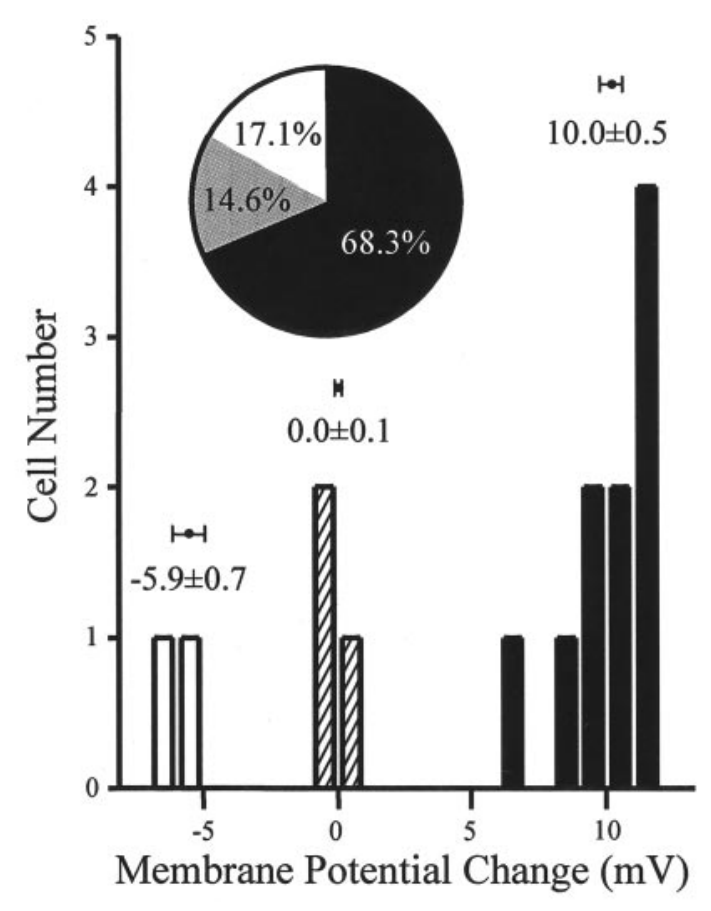

Figure 1. AP neurons respond to ORX-A application. AP neurons can be divided into three groups in accordance with their responses to $10^{-8}$ M ORX-A exposure (depolarized, $n=10$; hyperpolarized, $n=2$; with no effect, $n=3$ ). Inset, Pie chart showing that $10^{-8}, 10^{-9}$, and $10^{-10} \mathrm{M}$ ORX-A depolarized $68.3 \%$, hyperpolarized $17.1 \%$, and were without effect on $14.6 \%$ of AP neurons $(n=41)$.

\section{RESULTS}

The distinct morphology of the AP neurons after 1-3 d in culture, including phase-bright, 6 - to 8 - $\mu$ m-diameter soma and sometimes 2-5 $\mu \mathrm{m}$ long thin processes, are readily distinguished from the flat, large glial cells. In addition, AP neurons can also be distinguished from glial cells electrophysiologically (action potentials and sodium currents) (Ferguson et al., 1997). A total of 108 AP neurons were recorded with the whole-cell, patch-clamp technique. The mean resting membrane potential of neurons recorded in current clamp $(n=48)$ was $-59.24 \pm 0.87 \mathrm{mV}$, the mean input resistance was $3.57 \pm 0.22 \mathrm{G} \Omega$, and the action potential amplitude of neurons included in this study was always $>90 \mathrm{mV}$. The frequency of spontaneous action potentials in these AP neurons ranged from 0.2 to $9.9 \mathrm{~Hz}$ with a population average rate of discharge of $2.9 \pm 1 \mathrm{~Hz}$. Initial analysis of all current-clamp recordings showed that responsiveness of cells could be split into three distinctive subgroups according to the observed changes in membrane potential (depolarization, 67\%; hyperpolarization, $13 \%$; no effect, $20 \%$ ) in response to ORX-A $\left(10^{-8} \mathrm{M}\right)$ (Fig. 1). The inset in Figure 1 shows that $10^{-8}, 10^{-9}$, and $10^{-10}$ M ORX-A depolarized $68.3 \%$, hyperpolarized $17.1 \%$, and was without effect on $14.6 \%$ of AP neurons $(n=41)$. We could not identify any difference in the electrophysiological properties of these neurons, which corresponded with their responsiveness to ORX-A. In accordance with these observations, a neuron was thus deemed to be responsive if membrane potential changed by $>5 \mathrm{mV}$ after any particular experimental manipulation.

\section{ORX-A depolarizes AP neurons}

Based on the criteria established (see Materials and Methods), 41 of 48 cells $(85.4 \%)$ were classified as being responsive to changes 
in extracellular ORX-A (Responders), whereas the remainder of the cells (seven cells; 14.6\%) did not respond in a sustained manner and were therefore classified as Nonresponders. The vast majority of responsive cells $(80.5 \%$; 33 of 41$)$ demonstrated clear reversible depolarizations in response to bath application of ORX-A, the magnitude of which was concentration dependent, as illustrated in Figure $2 B$. During exposure of a neuron to $10^{-8} \mathrm{M}$ ORX-A from a control bath aCSF (Fig. $2 A$, top panel), cells exhibited rapid sustained depolarizations accompanied in most cases by a rapid increase in firing frequency of action potentials. After washout of ORX-A and replacement of the bath solution with control aCSF, the membrane potential and action potential frequency recovered to the control level. In 10 cells exposed to this same concentration of ORX-A, the mean amplitude of depolarization was $9.96 \pm 0.52 \mathrm{mV}$. Similar depolarizing responses of AP neurons to the exposure to $10^{-9}$ and $10^{-10} \mathrm{M}$ ORX-A are shown in Figure $2 A$. These depolarizing effects were found to be concentration dependent at concentrations ranging from $10^{-8}$ to $10^{-11} \mathrm{M}$, as illustrated by the concentration response curve presented in Figure $2 B\left(\mathrm{EC}_{50}=1.76 \times 10^{-10} \mathrm{M}\right)$. Although the depolarizing response of AP neurons to exposure to $10^{-11} \mathrm{M}$ ORX-A did not reach the criteria established (see Materials and Methods) to be defined as responders, all cells tested with this concentration were included in the analysis to complete the concentration-response curve.

\section{ORX-A does not influence net whole-cell potassium currents}

The modulation of voltage-gated potassium conductances has been shown to be important in the regulation of neuronal excitability. Orexin-B has been reported to decrease potassium conductance (Ivanov and Aston-Jones, 2000) or reduce afterhyperpolarization (Horvath et al., 1999) in locus ceruleus neurons. Therefore, we used voltage-clamp techniques to examine the effects of ORX-A on net whole-cell potassium currents evoked by depolarizing voltage steps. Figure $3 A$ illustrates the whole-cell currents recorded in response to depolarizing voltage steps applied from a holding potential of $-100 \mathrm{mV}$ in $20 \mathrm{mV}$ increments before and after bath application of $10^{-8}$ M ORX-A, showing no clear effect of ORX-A on area postrema on either the peak or sustained current. In all of the neurons tested $(n=20$ of 20), application of ORX-A $\left(10^{-8} \mathrm{M}\right)$ did not affect $\mathrm{K}^{+}$conductances of area postrema neurons at every voltage level, as illustrated in the group data presented in Figure $3 B$.

\section{ORX-A activates nonselective cationic conductances of AP neurons}

In view of the considerable literature demonstrating peptidergic effects on neuronal excitability mediated by modulation of nonselective cationic conductances (NSCCs), we subsequently used slow voltage ramps $[-100-0 \mathrm{mV}(10 \mathrm{sec})$ after a prepulse of -100 $\mathrm{mV}(500 \mathrm{msec})]$ to determine whether ORX-A influenced AP neurons as a consequence of activation of such conductances. The data presented in the top panel of Figure $4 A$ show average currents recorded from an AP neuron in response to such ramps (each trace is the mean of five ramps) recorded before, during, and after bath administration of ORX-A $\left(10^{-8} \mathrm{M}\right)$. The bottom panel of Figure $4 A$ shows the difference current (i.e., ORX-Ainduced current) obtained by subtracting control ramps from those obtained during ORX-A. Application of ORX-A $\left(10^{-8} \mathrm{M}\right)$ activated the NSCCs, and 5 min after washout of ORX-A and replacement of the bath solution with aCSF, the NSCCs recov-
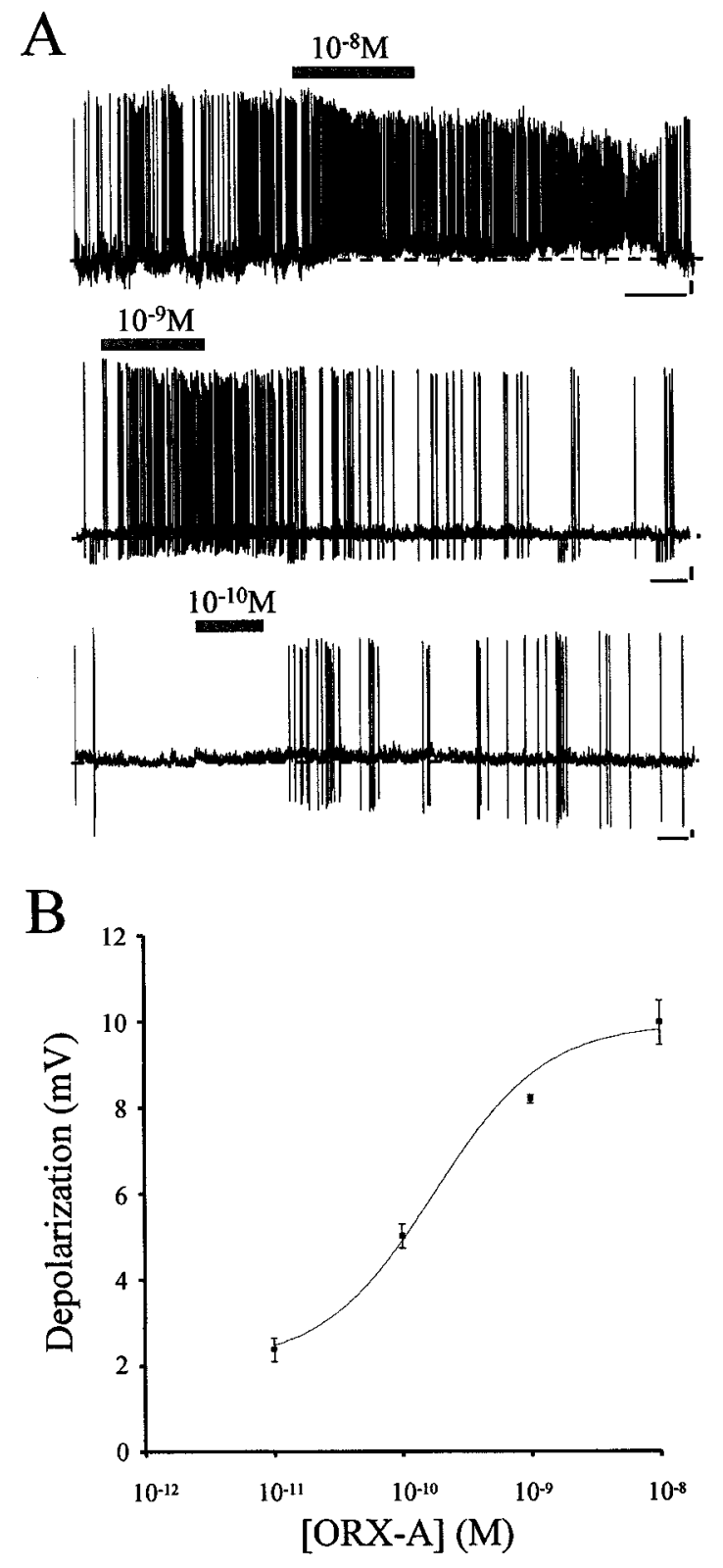

Figure 2. ORX-A depolarizes AP neurons. A, Bath application of various concentrations $\left(10^{-8}\right.$ to $10^{-11} \mathrm{M}$ ) of ORX-A depolarized $68.8 \%$ (33 of 48 ) of the AP neurons tested. During exposure to ORX-A from a control bath aCSF, AP neurons exhibited rapid sustained depolarizations accompanied in most cases by a rapid increase in firing frequency of action potentials. After washout of ORX-A and replacement of the bath solution with control aCSF, the membrane potential and action potential frequency returned to the control level. ORX-A application is represented by the horizontal bar above each trace. Calibration: $60 \mathrm{sec}, 10 \mathrm{mV}$. The dashed line indicates the baseline of potentials. $B$, Depolarization of AP neurons by ORX-A is concentration dependent. Changes in membrane potential measured during responses to $10^{-11}(n=5), 10^{-10}(n=14), 10^{-9}(n=4)$, and $10^{-8}(n=10)$ M extracellular ORX-A were plotted against bath ORX-A concentrations. Data change presented as mean \pm SEM data was fitted to a sigmoid concentration-response function, and the corresponding curve was overlaid; $\mathrm{EC}_{50}=1.76 \times 10^{-10} \mathrm{M}$.

ered toward control levels. Interestingly, as illustrated by the difference current shown in Figure $3 A$, we often saw increased noise in the depolarized range, which may be indicative of effects of ORX-A on additional, as yet unidentified channels. Similar 


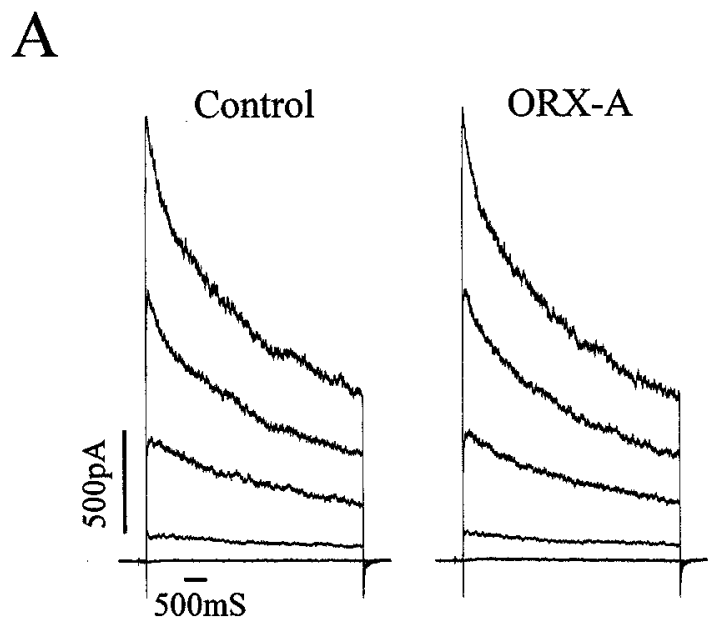

B

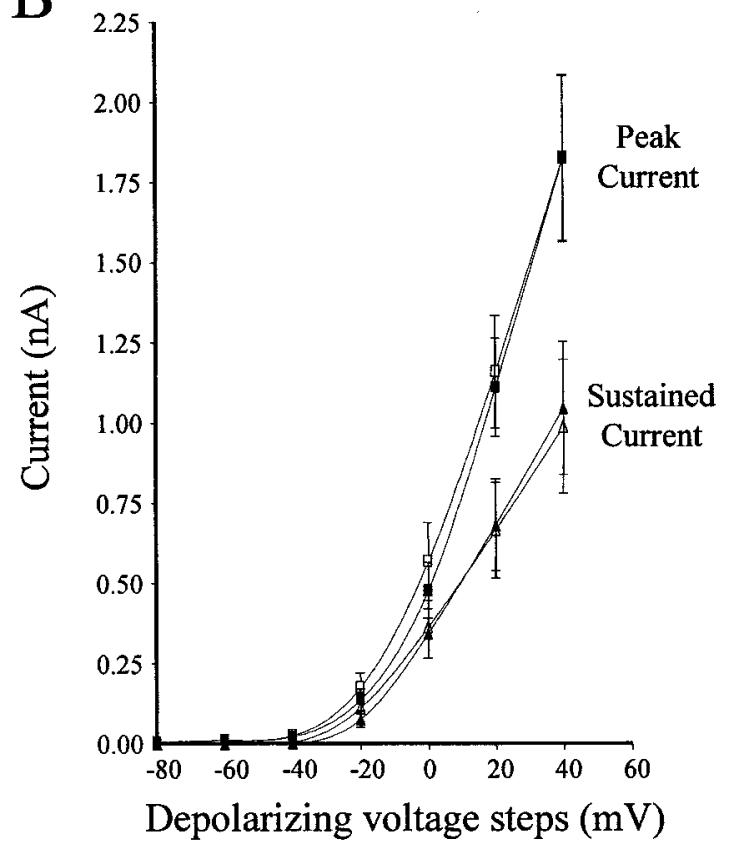

Figure 3. ORX-A does not influence net whole-cell potassium currents. $A$, Whole-cell net $\mathrm{K}^{+}$currents isolated from area postrema neurons (with $0.1 \mu \mathrm{M}$ TTX in aCSF) evoked by $20 \mathrm{mV}$ voltage steps $(5 \mathrm{sec})$ from -100 $\mathrm{mV}$ holding potential to $+40 \mathrm{mV}$ were unaffected by ORX-A exposure. $B$, Summary data of $\mathrm{K}^{+}$conductances recorded before (solid) and after (open) extracellular application of ORX-A $\left(10^{-8} \mathrm{M}\right)$ were not different at either the peak (squares) or the sustained currents (triangles).

effects of ORX-A $\left(10^{-8} \mathrm{M}\right)$ were observed in 14 of $20(70 \%)$ cells tested, a proportion that closely matches the proportion of AP neurons identified as being depolarized by ORX-A in our current-clamp experiments. Mean ORX-A-evoked currents for this group of responsive neurons are presented in Figure $4 B$, with these observations suggesting a reversal potential of $-43.57 \pm$ $5.43 \mathrm{mV}(n=14)$.

\section{DISCUSSION}

Several lines of evidence have shown that ORX acts in the CNS to modulate feeding, sleep-wakefulness, neuroendocrine homeostasis, and autonomic regulation. The distribution of ORX-IR axons and their varicose terminals in area postrema,

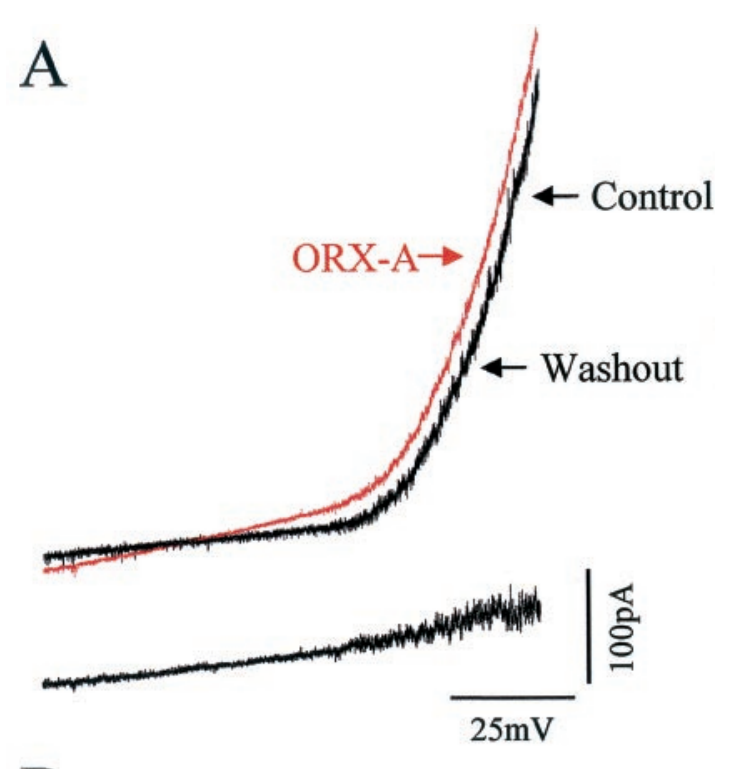

B

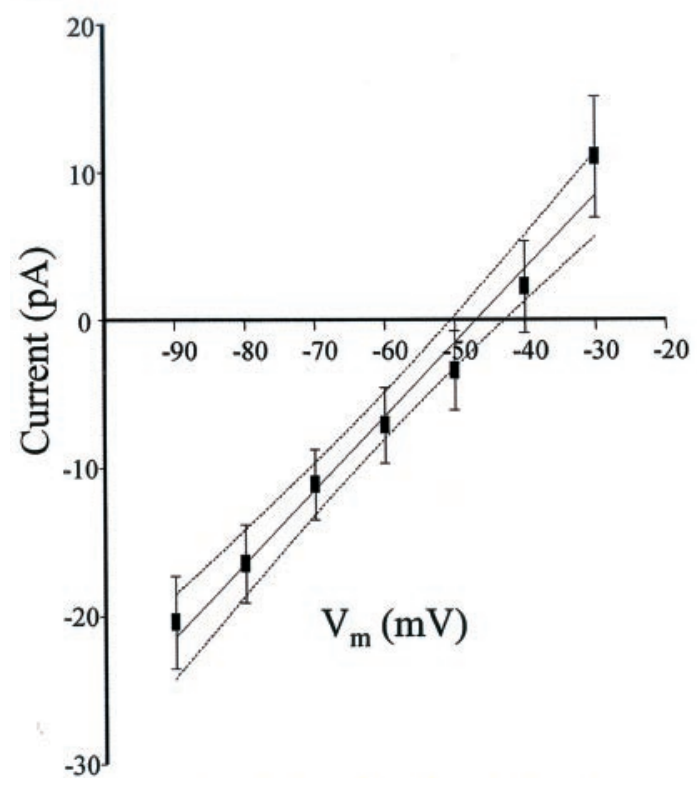

Figure 4. ORX-A activates nonselective cationic conductance in AP neurons. A, Top panel, Mean whole-cell currents (each trace is the mean of 5 ramps $)$ evoked from slow depolarizing $(10 \mathrm{mV} / \mathrm{sec})$ voltage ramps before, during, and after exposure to ORX-A $\left(10^{-8} \mathrm{M}\right)$. Bottom panel, Difference current obtained by subtracting the control current from the current recorded during ORX-A application. This represents the ORXA-evoked current. $B$, Mean ORX-A-evoked current for responsive neurons $(n=14)$ and its $95 \%$ confidence interval.

combined with the established involvement of ORX-A in the central modulation of feeding (Sakurai et al., 1998) and cardiovascular function (Shirasaka et al., 1999), suggest that the area postrema represents a significant site for potential neuroregulatory actions of this peptide. The data from this study are the first to demonstrate direct effects of ORX-A on area postrema neurons and, in addition, represent the first report of direct effects of this peptide on nonselective cationic conductances.

A significant issue in all studies using either acutely dissociated or cultured neurons is the degree to which the properties of these neurons match those of the cell in vivo. We have developed a 
methodology in these studies in which dissociated AP neurons are prepared from adult as opposed to neonatal tissue (Hay and Lindsley, 1995; Hay et al., 1996), which alleviates the likelihood of developmental changes influencing recorded properties. Our ability to completely isolate AP from all surrounding tissue also ensures that the cells we have recorded were derived exclusively from the AP. These dissociated AP neurons also show properties similar to those reported by other groups (Hay and Lindsley, 1995), as well as for AP neurons in tissue slice preparations (Jahn et al., 1996), and demonstrate patterns of spontaneous activity similar to those reported for AP neurons in vivo (Papas et al., 1990). Finally, the demonstration of effects of ORX on these dissociated cells argues strongly that the use of trypsin in the dissociation procedure has not permanently stripped these cells of their membrane-located peptide receptors.

Our initial current-clamp studies clearly illustrate the ability of ORX-A to influence the membrane potential of what appears to be a subpopulation of AP neurons. The fact that these effects were observed on dissociated cells indicates that they are the result of direct actions on the recorded neuron. The present lack of specific ORX receptor antagonists precluded identification of the specific ORX receptor mediating these effects. However, the clear reversibility and concentration dependence of these effects argue strongly that they are receptor mediated.

Previous studies have reported that ORX-B decreases potassium conductances (Ivanov and Aston-Jones, 2000) and reduces afterhyperpolarizations (Horvath et al., 1999) in locus ceruleus neurons. In view of the accepted role of potassium conductances in controlling neuronal excitability throughout the brain as well as in the area postrema (Hay and Lindsley, 1995), we subsequently examined whether the effects of ORX-A on these neurons might be mediated at least in part by similar modulatory actions of this peptide on voltage-gated potassium currents. Surprisingly, our data demonstrated that ORX-A had no effects on whole-cell, voltage-dependent potassium currents. In view of the clear lack of effect of the peptide on these mixed currents, they were not dissected further for the current analysis, although separate experiments have shown that $\mathrm{I}_{\mathrm{A}}, \mathrm{I}_{\mathrm{K}}$, and $\mathrm{I}_{\mathrm{D}}$ all likely contribute to the total current we examined. However, it should be emphasized that we have not evaluated potential effects of ORX on the iberiotoxin-sensitive $\mathrm{Ca}^{2+}$-activated potassium channel, which has also been reported in AP neurons ( $\mathrm{Li}$ and Hay, 2000).

The nonselective cationic conductance is a membrane channel for cations not specific for $\mathrm{Na}^{+}, \mathrm{K}^{+}$, or $\mathrm{Ca}^{2+}$. Its reversal potential is unaffected by changes in $\mathrm{Cl}^{-}$concentration and $\mathrm{pH}$, and it is voltage independent (Kramer and Zucker, 1985). Nonselective cationic conductances have been shown to participate in controlling neuronal excitability in many systems, including generation of the depolarizing phase of bursting pacemaker activity in Aplysia burst-firing neurons (Kramer and Zucker, 1985), and in the intrinsic activation of rat supraoptic neurons by hyperosmotic stimuli (Bourque, 1989), neurotensin (Kirkpatrick and Bourque, 1995), and P2 purinoceptor agonists (Hiruma and Bourque, 1995). In addition, previous work from our laboratory demonstrated that activation of the calcium receptor in neurons of the subfornical organ, a forebrain circumventricular structure, results in profound effects on neuronal excitability through metabotropic actions on a nonselective cation channel (Washburn et al., 1999). The results from the current study illustrate for the first time the effect of ORX-A on an NSCC in area postrema neurons. Extracellular application of ORX-A activated NSCCs in reversible manner in a proportion of AP neurons similar to that which our current-clamp recordings demonstrated to be depolarized by this peptide. The conductance of this NSCC is $0.497 \pm 0.031 \mathrm{nS}$. We usually held AP neurons between -52 and $-53 \mathrm{mV}$ before ORX-A $\left(10^{-8} \mathrm{M}\right)$ administration. At this potential, ORX-A would be expected to activate the NSCCs as a 2.5-3 pA inward current (Fig. 4B), which we calculate to evoke an $8-11 \mathrm{mV}$ depolarization (average input resistance of AP neurons is 3.6 $\mathrm{G} \Omega)$, which is close to the average depolarization $(9.96 \pm 0.52$ $\mathrm{mV}$ ) caused by $10^{-8} \mathrm{M}$ ORX-A application.

In conclusion, this study provides the first evidence that orexin-A directly activates area postrema neurons by modulating nonselective cationic conductance, whereas it does not affect the $\mathrm{K}^{+}$channel activities. These findings suggest that orexin may have a functional role in the regulation of feeding behavior and cardiovascular and autonomic nervous systems at the AP level.

\section{REFERENCES}

Borison HL (1974) Area postrema: chemoreceptor trigger zone for vomiting-is that all? Life Sci 14:1807-1817.

Bourgin P, Huitron-Resendiz S, Spier AD, Fabre V, Morte B, Criado JR, Sutcliffe JG, Henriksen SJ, de Lecea L (2000) Hypocretin-1 modulates rapid eye movement sleep through activation of locus ceruleus neurons. J Neurosci 20:7760-7765.

Bourque CW (1989) Ionic basis for the intrinsic activation of rat supraoptic neurones by hyperosmotic stimuli. J Physiol (Lond) 417: 263-277.

de Lecea L, Kilduff TS, Peyron C, Gao X, Foye PE, Danielson PE, Fukuhara C, Battenberg EL, Gautvik VT, Bartlett FS, Frankel WN, Van Den Pol AN, Bloom FE, Gautvik KM, Sutcliffe JG (1998) The hypocretins: hypothalamus-specific peptides with neuroexcitatory activity. Proc Natl Acad Sci USA 95:322-327.

Edwards GL, Ritter RC (1981) Ablation of the area postrema causes exaggerated consumption of preferred foods in the rat. Brain Res 216:265-276.

Ferguson AV, Marcus P (1988) Area postrema stimulation induced cardiovascular changes in the rat. Am J Physiol 255:R855-R860.

Ferguson AV, Bicknell RJ, Carew MA, Mason WT (1997) Dissociated adult rat subfornical organ neurons maintain membrane properties and angiotensin responsiveness for up to 6 days. Neuroendocrinology 66:409-415.

Ferrario CM, Barnes KL, Szilagyi JE, Brosnihan KB (1979) Physiological and pharmacological characterization of the area postrema pressor pathways in the normal dog. Hypertension 1:235-245.

Hara J, Beuckmann CT, Nambu T, Willie JT, Chemelli RM, Sinton CM, Sugiyama F, Yagami K, Goto K, Yanagisawa M, Sakurai T (2001) Genetic ablation of orexin neurons in mice results in narcolepsy, hypophagia, and obesity. Neuron 30:345-354.

Hay M, Lindsley KA (1995) Membrane properties of area postrema neurons. Brain Res 705:199-208.

Hay M, Hasser EM, Lindsley KA (1996) Area postrema voltageactivated calcium currents. J Neurophysiol 75:133-141.

Hiruma H, Bourque CW (1995) P2 purinoceptor-mediated depolarization of rat supraoptic neurosecretory cells in vitro. J Physiol (Lond) 489:805-811.

Horvath TL, Peyron C, Diano S, Ivanov A, Aston-Jones G, Kilduff TS, Van Den Pol AN (1999) Hypocretin (orexin) activation and synaptic innervation of the locus coeruleus noradrenergic system. J Comp Neurol 415:145-159.

Hyde TM, Miselis RR (1983) Effects of area postrema/caudal medial nucleus of solitary tract lesions on food intake and body weight. Am J Physiol 244:R577-R587.

Ivanov A, Aston-Jones G (2000) Hypocretin/orexin depolarizes and decreases potassium conductance in locus coeruleus neurons. NeuroReport 11:1755-1758.

Jahn K, Bufler J, Weindl A, Arzberger T, Hatt H (1996) Patch-clamp study on membrane properties and transmitter activated currents of rabbit area postrema neurons. J Comp Physiol [A] 178:771-778.

Kirkpatrick K, Bourque CW (1995) Effects of neurotensin on rat supraoptic nucleus neurones in vitro. J Physiol (Lond) 482:373-381.

Kramer RH, Zucker RS (1985) Calcium-dependent inward current in Aplysia bursting pace-maker neurones. J Physiol (Lond) 362:107-130.

Kunii K, Yamanaka A, Nambu T, Matsuzaki I, Goto K, Sakurai T (1999) Orexins/hypocretins regulate drinking behaviour. Brain Res 842:256-261.

Kuru M, Ueta Y, Serino R, Nakazato M, Yamamoto Y, Shibuya I, Yamashita H (2000) Centrally administered orexin/hypocretin activates HPA axis in rats. NeuroReport 11:1977-1980.

Leslie RA (1986) Comparative aspects of the area postrema: fine- 
structural considerations help to determine its function. Cell Mol Neurobiol 6:95-120.

Li Z, Hay M (2000) 17- $\beta$-estradiol modulation of area postrema potassium currents. J Neurophysiol 84:1385-1391.

Marshall JF, Teitelbaum P (1974) Further analysis of sensory inattention following lateral hypothalamic damage in rats. J Comp Physiol Psychol 86:375-395.

Oltmans GA, Harvey JA (1976) Lateral hypothalamic syndrome in rats: a comparison of the behavioral and neurochemical effects of lesions placed in the lateral hypothalamus and nigrostriatal bundle. J Comp Physiol Psychol 90:1051-1062.

Papas S, Smith P, Ferguson AV (1990) Electrophysiological evidence that systemic angiotensin influences rat area postrema neurons. Am J Physiol 258:R70-R76.

Peyron C, Tighe DK, Van Den Pol AN, de Lecea L, Heller HC, Sutcliffe JG, Kilduff TS (1998) Neurons containing hypocretin (orexin) project to multiple neuronal systems. J Neurosci 18:9996-10015.

Reilly CE (1999) I. Mutation in the hypocretin (orexin) receptor 2 gene causes canine narcolepsy. J Neurol 246:985-986.
Rodgers RJ, Halford JC, Nunes de Souza RL, Canto de Souza AL, Piper DC, Arch JR, Blundell JE (2000) Dose-response effects of orexin-A on food intake and the behavioural satiety sequence in rats. Regul Pept 96:71-84.

Sakurai T, Amemiya A, Ishii M, Matsuzaki I, Chemelli RM, Tanaka H, Williams SC, Richardson JA, Kozlowski GP, Wilson S, Arch JR, Buckingham RE, Haynes AC, Carr SA, Annan RS, McNulty DE, Liu WS, Terrett JA, Elshourbagy NA, Bergsma DJ, et al (1998) Orexins and orexin receptors: a family of hypothalamic neuropeptides and G-protein-coupled receptors that regulate feeding behavior. Cell 92:573-585.

Shirasaka T, Nakazato M, Matsukura S, Takasaki M, Kannan H (1999) Sympathetic and cardiovascular actions of orexins in conscious rats. Am J Physiol 277:R1780-R1785.

Washburn DL, Smith PM, Ferguson AV (1999) Control of neuronal excitability by an ion-sensing receptor (correction of anion-sensing). Eur J Neurosci 11:1947-1954.

Wislocki GB, Putnam TJ (1920) Note on the anatomy of the areae postremae. Anat Rec 19:281-287. 